\title{
Memória e espaço público: reflexões sobre a praça Wandyck Dumont em Bocaiuva/MG e as suas reformas ao longo do tempo
}

\author{
Memory and public space: reflections on Wandyck Dumont Square in \\ Bocaiuva/MG and its renovations over the time
}

\author{
Guilherme Henrique Almeida Araújo', Anete Marília Pereira"
}

\section{RESUMO}

As intervenções espaciais promovidas nos espaços públicos urbanos no decorrer do tempo expõem aspectos significativos da memória social de uma dada população. Apreender os efeitos de tais transformações implica falar de sentimentos, significados e emoções de um espaço que é, antes de tudo, vivido. Diante dessa premissa, o presente artigo tem por objetivo relacionar a memória da população da cidade de Bocaiúva com as transformações na estrutura física pelas quais a Praça WanDyck Dumont passou ao longo do tempo. Metodologicamente foi realizada a pesquisa bibliográfica e documental, bem como trabalho de campo, momento em que foram coletadas as narrativas orais por meio de entrevista. Como resultados, foi possível constatar que muitos moradores compreendem o processo de modernização da cidade, o que inclui o da praça em análise, mas criticam a forma como as intervenções foram realizadas e defendem a necessidade de uma valorização maior dos marcos que estão imbuídos de significados ou que guardam na sua estrutura um pouco da memória de seu povo.

Palavras-chave: Espaço público; Memória; Bocaiuva

\section{ABSTRACT}

Spatial interventions in urban public spaces over time interfere in significant aspects of the social memory of a given population. To apprehend the effects of such transformations it is necessary to talk about feelings, meanings and emotions of a space where people live. Therefore, this article aims to relate the memory of Bocaiúva's inhabitants with the transformations in the physical structure that WanDyck Dumont Square has undergone over time. The methodology used for this research includes bibliographical and documentary research, as well as fieldwork, when oral narratives were collected through interviews. As a result, it was evident that many residents understand the modernization process of the city, which includes the square under analysis, however, they also criticize the way the interventions were carried out and defend that the landmarks should not be underestimated since they are meaningful and also belong to the community's memory.

Keywords: Public Space; Memory; Bocaiuva

'Mestrando em Geografia pelo Programa de Pós Graduação em Geografia, Universidade Estadual de Montes Claros, Montes Claros, MG. E-mail: guilherme.halmeida@hotmail.com ORCID: https://orcid.org/0000-0002-0458-7908

"Doutora em Geografia. Professora do Programa de Pós-Graduação em Geografia, Universidade Estadual de Montes Claros, Montes Claros, MG. E-maiL: anete.pereira@unimontes.br ORCID: https://orcid.org/0000-0001-7084-7109 


\section{INTRODUÇÃO}

Cada cidade tem, na sua história, pontos de referência que pertencem à sua memória e são fundamentais para a identidade e sentimento de pertencimento das pessoas em relação ao meio em que estão inseridas. Os significados dos locais dependem muito da importância que a população imprime sobre eles. São praças que funcionam como pontos de encontro, centros comerciais onde aglomeram grande contingente de pessoas, elementos arquitetônicos, como igrejas, prédios e edifícios públicos que se tornam símbolos de uma determinada localidade.

Não obstante, a sustentabilidade de tais símbolos depende de como a cidade determina a permanência deles em sua malha urbana. Na medida em que se desenvolve e novas necessidades vão surgindo, alguns espaços passam por modificações para se adequarem aos ideais políticos e sociais de desenvolvimento e nem sempre estão de acordo com as expectativas das pessoas, sobretudo quando não há consulta popular. Muitos espaços também têm seus usos e dinâmicas alterados, o que pode ser determinante para o abandono dos mesmos, deteriorando-se ao longo do tempo, caso nenhuma medida de intervenção seja tomada.

Esses processos de modificação e deterioração podem acontecer em espaços de uso público que estão ligados à história de vida de alguns indivíduos. Eles têm a sua memória ferida quando já não reconhecem na malha urbana traços importantes dos lugares que sediaram suas vivências e que fizeram parte de sua trajetória. Por conseguinte, é importante entender quais são as dinâmicas que caracterizam determinados espaços, antes de se propor uma modificação capaz de descaracterizá-los ou mudar drasticamente o curso do seu uso.

Assim sendo, artigo tem por objetivo relacionar a memória da população da cidade de Bocaiúva com as transformações físicas pelas quais a Praça WanDyck Dumont passou ao longo do tempo. A referida praça é considerada um 
ponto de referência dentro da cidade, tanto pela localização, quanto pelo seu significado histórico, social e político. Para tanto, utilizou-se uma metodologia que associou a pesquisa bibliográfica e documental com o trabalho de campo. A história oral mostrou-se como um procedimento metodológico importante para a obtenção de conhecimento. Por meio de relatos orais de moradores mais antigos da cidade foi possível entender importância e significados que a praça em estudo possui. Foram entrevistados três moradores, escolhidos aleatoriamente, com faixa etária entre sessenta e oitenta anos que, ao lembrarem de fatos, lugares e experiências pessoais, auxiliaram na produção de uma memória que é, também, social. Inicialmente, foram questionados sobre os elementos que constituíam a Praça WanDyck Dumont no passado e que fazem parte da sua memória. Em seguida, solicitou-se que se posicionassem a respeito dessas reformas e que fosse feita uma comparação entre o momento atual e épocas de outrora. As suas memórias e opiniões foram transcritas e confrontadas com produções científicas. Optou-se pelo recorte temporal de 1940 até a atualidade, porque foi nesse período em que ocorreram as mudanças mais expressivas na praça das quais se tem registros, bem como moradores que se recordam das mesmas.

O artigo está estruturado em dois tópicos, sendo que o primeiro traz uma abordagem teórica sobre memória e espaços públicos, e o segundo apresenta o resultado das entrevistas com os moradores da cidade.

\section{ESPAÇO PÚBLICO E MEMÓRIA}

No Brasil, segundo o censo do IBGE de 2010, mais de $84 \%$ da população reside em espaços urbanos. Esse número crescente de pessoas vivendo nas cidades é algo que viceja a elaboração de estratégias de planejamento urbano que sejam mais eficientes, para que a cidade possa oferecer aos seus habitantes condições adequadas de moradia, mobilidade, saúde, segurança e educação. A resposta a esses anseios, no Brasil, veio por intermédio da criação de uma série 
de leis, dentre elas o Estatuto da Cidade (Lei nº 10.257 de 10 de julho de 2001), que orientam o processo de gestão urbanística, vislumbrando cidades mais democráticas (DIAS; JÚNIOR, 2017).

No entanto, sabe-se que as lógicas de produção do espaço urbano ainda estão pautadas na segregação, aos moldes do sistema capitalista, uma vez que os interesses do mercado imobiliário se sobrepõem às questões sociais. Nessa vereda, o estímulo ao lazer e à vida pública em espaços de uso comum é deixado de lado para que sejam atendidos os interesses de uma pequena parcela detentora de capital, o que reforça a existência de problemas de ordem econômica, social e política do país. Sobarzo (2006) chama atenção para a escassez de iniciativas do Estado que sejam especificamente voltadas para a melhoria das condições infraestruturais e para a criação de novos espaços públicos, uma vez que não há verba designada exclusivamente para esses fins. Isto posto, os espaços existentes que não possuem nenhum atrativo se tornam meros espaços de passagem e de pouca permanência de pessoas e práticas de lazer, deixando-os subutilizados e à mercê de deteriorações diversas (LIPAI, 2006).

No caso em tela, é de se constatar a relevância dos espaços de dimensão pública como instrumentos de mudança da realidade das cidades contemporâneas, que, se reestruturados com base nas necessidades humanas e no respeito à memória coletiva, passam a estimular a vivacidade desses centros. Os espaços públicos assumem uma multiplicidade de sentidos, formas e tamanhos que possibilitam uma extensa variedade de usos pelos habitantes da cidade, sendo assim, idealmente, espaços de integração social. Podem ser pensados, portanto, como plurais e condensadores do vínculo entre a sociedade, o território, a política e a questões de sociabilidade no espaço apreendido. A respeito dos sentidos que os espaços públicos urbanos possuem, Carlos (2016, p.130) pontua: 
O espaço público, por sua vez, tem uma multiplicidade de sentidos para a sociedade, em função da cultura, dos hábitos e dos costumes, que não pode ser negligenciado. Nesse caminho, é substancialmente troca social, movimento, e relaciona-se, portanto, à atividade plena do indivíduo, que, pela relação com o outro, é definidora dos seus destinos [...] Diferenciando-se do nível do privado, contempla a possibilidade do acaso e do inesperado, sendo também o lugar da festa e dos referenciais constituidores da identidade.

Compreendem, em consonância com Alex (2011, p.19) “desde uma calçada até a paisagem vista da janela (...)" abrangem, também, locais que são destinados ao uso cotidiano "cujas formas mais conhecidas são as ruas, as praças e os parques." A função que desempenham no contexto da cidade determina a importância da existência de tais elementos na paisagem urbana.

Eles possuem função social (à medida que proporcionam encontro e lazer, promovendo a socialização dos indivíduos), função organizacional (organizam a infraestrutura da cidade e configuram o desenho urbano), função ecológica (estruturam áreas de proteção ao ambiente) e função cultural (fortalecem a identidade local) (BORTOLO, 2013a, p.52).

Os espaços públicos fazem parte da dinâmica das cidades, podendo estar ligados ao núcleo central, circundados por edifícios de cunho político, econômico, institucional e religioso - é o caso das praças - ou estar espalhados em pontos distintos da malha urbana, de forma a estruturá-la. Por serem tão presentes no cotidiano da vida citadina, são espaços de ação da cidadania e despertam sentimento de pertença ao lugar.

Por outro lado, ao resgatar as ideias de Lefebvre (2000), Serpa (2004) salienta que as cidades modernas são concebidas pautadas em princípios, que, por vezes, negam a unicidade do local. Elas possuem características universais que são repetidas indiscriminadamente, tendo como produto espaços públicos morfologicamente parecidos uns com os outros, objetivando uma rápida assimilação de suas formas para serem implementados em bairros onde existem interesses imobiliários. Esses espaços homogêneos se opõem aos espaços que surgem espontaneamente, com base nas vivências e percepções de comunidades, que imprimem neles, suas preferências e expressões culturais (SERPA, 2004). É visto, por conseguinte, como um produto institucional do Estado 
ou das iniciativas privadas que tendem a aniquilar as diferenças e contradições de usos indesejáveis, ou apagar da malhar urbana, aqueles espaços que têm alguma ligação com o passado e que, na visão desses agentes, não se compatibilizam com a atualidade.

No tocante ao assunto, Gomes (2018) trata a homogeneidade dos espaços além do viés morfológico e discute essa questão a partir das relações sociais de grupos que buscam localidades onde possam interagir com seus pares. Segundo o autor, é comum observar esse comportamento em pessoas que não se dispõem a estar em espaços que sejam frequentados por indivíduos de classes sociais distintas das suas. Em um determinado momento do dia, um dado espaço público pode vir a ser frequentado apenas por quem se identifica com os usos e funções que o tipificam, ou pelas pessoas que ali estão por afinidade. Desta maneira, além dos espaços assumirem uma morfologia semelhante a outros ao redor do mundo, se homogeneízam pelo tipo de usuário que os frequentam, ação que gera segregações e estigmatiza determinadas regiões da cidade como elitizadas ou marginais.

É nesse ponto que Serpa (2004) assevera que existem dois tipos de acessibilidade - a física e a simbólica. A primeira refere-se aos aspectos projetuais do espaço que possibilitam a plena utilização do mesmo, materializados na inexistência de barreiras impenetráveis - escadarias que restringem o acesso de cadeirantes, muros, grades, calçadas irregulares, etc. Para ele, "um espaço acessível a todos deve significar (...) algo mais do que o simples acesso físico a espaços 'abertos' de uso coletivo" (SERPA, 2004, p.22), ou seja, deve também emitir sinais - acessibilidade simbólica - que dão a entender que todo e qualquer tipo de pessoa possa utilizá-lo livremente. No bojo dessa discussão, o autor atesta que o espaço público é constantemente privatizado em todos os lugares da cidade, sem que haja uma distinção de classe. Tanto em bairros de classe média, quanto em bairros de classe com um perfil mais popular, 
os espaços passam por processos de territorialização que limitam o uso a uma finalidade específica destinada a um tipo de usuário.

Embora essa tendência a homogeneizar o espaço seja uma realidade da maioria das cidades, percebe-se que movimentos resistentes a esses processos também são cada vez mais comuns. Cumpre salientar que indivíduos que se sentem excluídos, ou têm ferida a memória, recalcitram as ordens impostas pelos grupos dominantes e passam a reivindicar os seus direitos de pertencer ao espaço com o qual se identificam, através da imposição dos seus meios de uso e apropriação. Essas práticas "subversivas" de utilização do espaço são chamadas por Leite (2002) de contra-usos e culminam na co-presença de indivíduos de camadas sociais distintas, que se cruzam no mesmo espaço, conferindo a ele uma característica heterogênea (ANDRADE; BAPTISTA, 2015).

Para que esses conflitos sejam menos frequentes há que se pensar em novas formas de produzir o espaço público, embasadas em ferramentas que considerem a participação popular como parte constituinte do planejamento. Del Rio (1990) pontifica que as comunidades precisam se organizar para ajudarem, efetivamente, nos planos e projetos, garantindo assim, a legitimidade do processo participativo.

Face ao que foi discutido, entende-se que o espaço público possui uma forte representatividade na vida das pessoas da cidade por estar presente no cotidiano de cada habitante. Há, nesses lugares, dinâmicas de todas as ordens como observado por Gehl (2015, p.22):

As atividades sociais incluem uma extensa gama de atividades diversas. Há muitos contatos passivos de ver e ouvir: observar as pessoas e o que está acontecendo [...] As pessoas cumprimentam-se e conversam com os conhecidos. Há encontros casuais e bate-papos em mercados, bancos de praça e em todos os lugares onde as pessoas tenham que esperar algo. [...] Às vezes, desses rápidos cumprimentos pode surgir um contato mais amplo. Novos assuntos e interesses comuns são discutidos. Novas amizades podem desabrochar [...].

A dinâmica de uma cidade tem relação direta com o movimento, com as experiências vividas pelos seus habitantes. Em outras palavras, tem relação com 
8 | Memória e espaço público: reflexões sobre a praça Wandyck Dumont em Bocaiuva - MG e as suas reformas ao longo do tempo

a memória produzida socialmente. Obviamente, o conceito de memória é bem mais complexo do que se apresenta nesse estudo de caso. Entende-se aqui que no seu significado está implícita a qualidade da relação existente entre as pessoas e determinado espaço. Abarca o conjunto de recordações, imagens, identidades e significados simbólicos presentes nas narrativas das pessoas ao se referirem a determinados espaços físicos na cidade. Tal como definido por Souza (2014, p. 104) "a memória é o instrumento que permite a atuação do passado no presente por meio das lembranças", ou seja, é uma forma de representação que possibilita criar uma imagem do passado, dos lugares representativos na construção identitária. Ortegosa (2009, s/p. ) ressalta que

\begin{abstract}
A arquitetura e os lugares da cidade constituem o cenário onde nossas lembranças se situam e, na medida em que as paisagens construídas fazem alusão a significados simbólicos, elas estão evocando narrativas relacionadas às nossas vidas. Assim, a maneira como interpretamos nossas experiências no espaço converte-se em nossa realidade e possibilita-nos dar significado ao nosso mundo físico. Com o passar do tempo, uma constelação de signos se estratificam na memória coletiva constituindo uma cidade análoga.
\end{abstract}

Como se pode negligenciar que as transformações dos espaços públicos não interferem no sentimento de pertença de uma dada população? Considerando que esses espaços estão intimamente ligados à suas histórias e vivências é importante mencionar que as reformas propostas pelo poder público precisam ser levadas adiante com total consentimento daqueles indivíduos que são os verdadeiros proprietários dos espaços públicos: as pessoas. A respeito das transformações desse espaços, Jacobs (2000, p. 437) corrobora:

Uma das idéias inconvenientes por trás dos projetos é a própria noção de que eles são conjuntos, abstraídos da cidade comum e separados. Pensar em recuperar ou melhorar os projetos como projetos é persistir no mesmo erro. $\mathrm{O}$ objetivo deveria ser costurar novamente esse projeto, esse retalho da cidade, na trama urbana e, ao mesmo tempo, fortalecer toda a trama ao redor.

É certo que não se pode apegar a estruturas muito antigas que já não condizem mais com o que é demandado na atualidade, não obstante, as 
transformações apenas serão válidas se todos os condicionantes, problemáticas, dinâmicas e expectativas ligadas à memória da cidade e do determinado espaço forem levadas em conta. Caso contrário, ele será uma total negação da sua própria essência e pode gerar controvérsias quanto a sua nova forma ou função.

As sucessivas transformações que ocorrem na cidade, na maioria das vezes, se revelam necessárias para acomodar novas funções que objetivam melhorar o seu funcionamento interno ou atender a ideais de modernidade. Essas reformas podem acontecer em vários pontos, notadamente na área de origem da cidade. Muitas pessoas referem-se a esses pontos com sentimentos saudosistas, por sentirem falta de elementos que compunham sua estrutura no passado, e que, após as reformas, não existem mais. Para tanto, Bosi (2003) acredita que a memória escolhe lugares privilegiados de onde se retira a sua seiva, com isso, as lembranças se apoiam nas pedras da cidade, que crescem em todas as direções, a partir da memória.

No intuito de preservar a memória urbana, as sociedades da virada do milênio passaram a romper com os ataques às heranças do passado, como era comum acontecer em períodos em que só era cultuado o novo. Atualmente, as cidades brasileiras estão imersas nessa tendência de valorizar discursos e projetos de restauração e preservação de elementos que fazem parte de sua história (ABREU, 2016).

Para o referido autor (2016, p.21) “o passado é uma das dimensões mais importantes da singularidade" e é exatamente essa busca pela individualidade que faz com que se encontre nas raízes das cidades, as características que as diferem das demais localidades. Marcos históricos emblemáticos e espaços públicos típicos que refletem a cultura das pessoas são exemplos de elementos que reforçam essa singularidade de um lugar. Arantes (2000) afirma que a 
construção social destes espaços politiza o espaço urbano (qualificando-o como espaço público), na medida em que cada lugar, para se legitimar perante o outro e a partir do qual se diferencia, precisa igualmente ser reconhecido publicamente em sua própria singularidade.

Diante do exposto é importante explorar a memória das pessoas relativa aos espaços públicos urbanos. Nessa esteira, os dizeres de Abreu (2016, p.25) se mostram condizentes com o que aqui é proposto, ao afirmar que "a memória individual pode contribuir, portanto, para a recuperação da memória das cidades. A partir dela, ou de seus registros, pode-se enveredar pelas lembranças das pessoas e atingir momentos urbanos que já passaram e formas espaciais que já desapareceram." Esse resgate é de suma importância para que informações valiosas sobre os espaços de dimensão pública não se percam no tempo e para que a cidade apresente em sua malha, características que denotam diversidade: a mistura de elementos urbanos antigos e novos (JACOBS, 2000).

\section{A PRAÇA WANDYCK DUMONT DE BOCAIÚVA E AS SUAS TRANSFORMAÇÕES}

\section{ENTRE AS DÉCADAS DE 1930 E 1990}

O município de Bocaiúva está localizado na porção norte do estado de Minas Gerais (figura 1) possui uma população total de 46.654 habitantes - sendo 36.600 residentes na área urbana e 10.054 na área rural (IBGE, 2010). De acordo com Ribeiro (1988) o crescimento urbano da cidade aconteceu de forma espontânea, com traçado irregular e salienta que o início da cidade se deu a partir da capela do Nosso Senhor do Bonfim e, posteriormente, em direção ao atual centro e à porção Nordeste, a partir da inauguração da Estrada de Ferro na década de 1920. 
Figura 1 - Mapa de localização do município de Bocaiuva

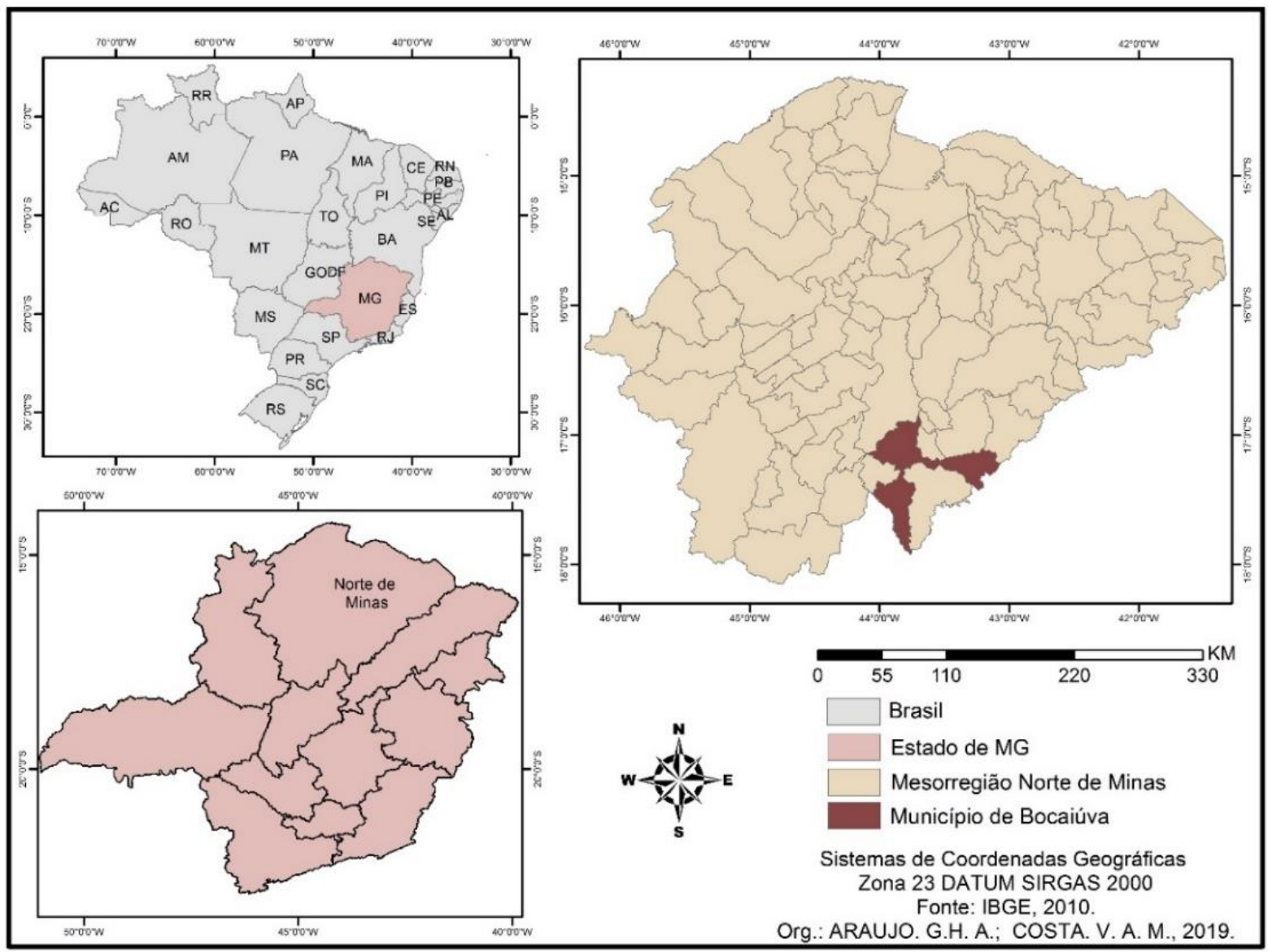

De acordo com a Secretaria Municipal de Meio Ambiente e Serviços Urbanos, Bocaiuva possui trinta e seis praças cadastradas. A figura 2 mostra a localização das praças na malha urbana e a partir dela percebe-se quais são os bairros contemplados por esses espaços públicos. O centro é o lugar com maior concentração de praças da cidade - 37,83\% do total - seguido do bairro Pernambuco que possui, dentro dos seus limites, $27,02 \%$ das praças. Os demais bairros, incluindo o Bonfim - primeiro bairro de Bocaiuva -, não são contemplados com muitas praças e juntos, possuem um percentual de 35,15\%, concentração inferior a do centro. Vale ressaltar que outros bairros nem sequer possuem tais espaços por serem bairros novos e pouco adensados ou por estarem localizados na zona periférica.

A área central de Bocaiúva é um ponto de referência para os moradores, por ser um núcleo de convergência de fluxos e por concentrar as principais 
12 | Memória e espaço público: reflexões sobre a praça Wandyck Dumont em Bocaiuva - MG e as suas reformas ao longo do tempo

atividades comerciais e de serviços. É nessa porção da cidade que se localiza a Praça WanDyck Dumont.

Figura 2 - Localização das praças na malha urbana de Bocaiuva - 2019

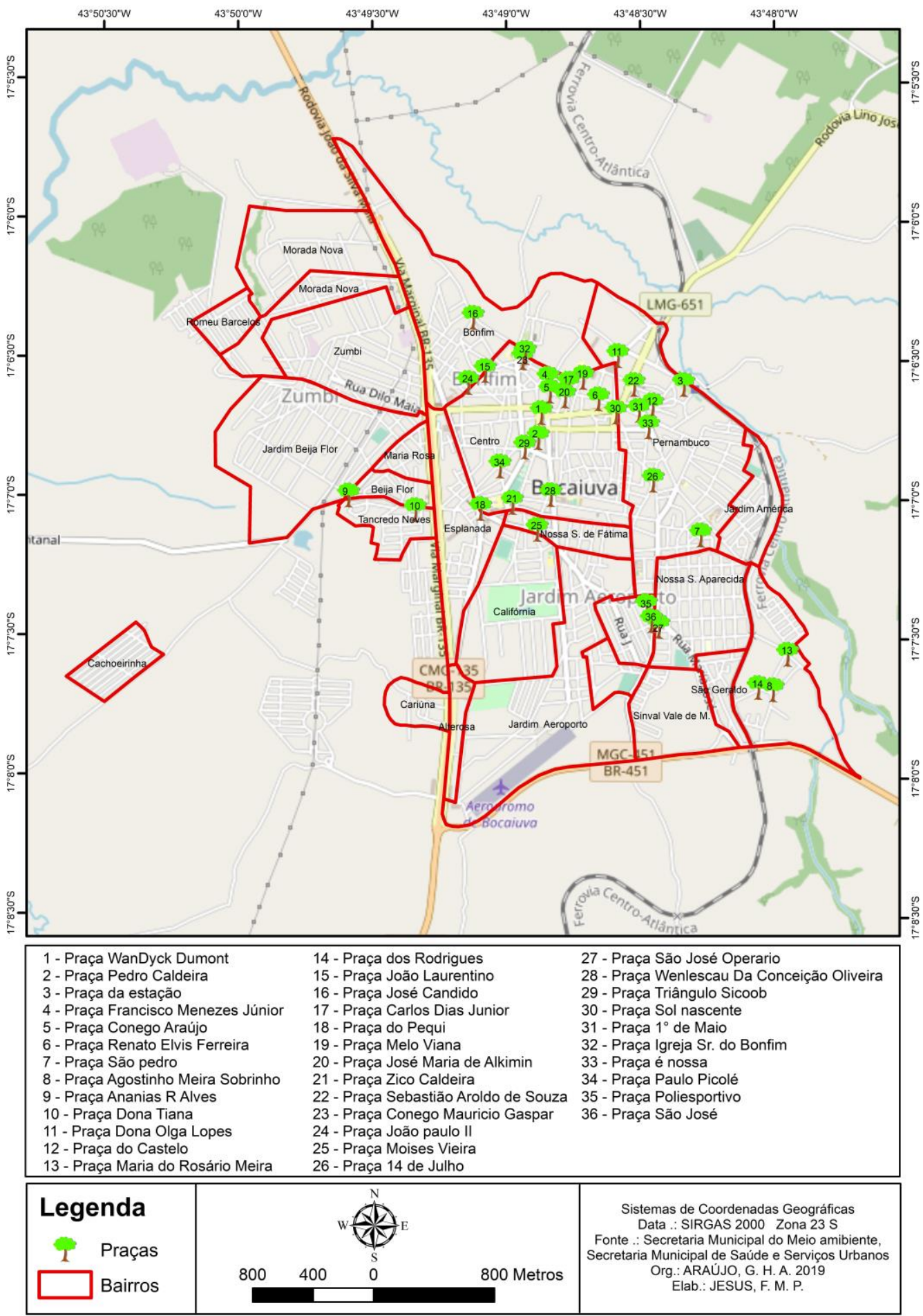


Acredita-se que por volta do ano de 1888 a Praça WanDyck Dumont, denominada nessa época de "Paço Municipal" (AMORIM, 1999, p.39), já existia na cidade de Bocaiuva, certamente com uma estrutura completamente diferente dos tempos atuais, sem calçamento ou qualquer tipo de pavimentação (figura 3). Ao longo dos anos, o referido espaço público foi denominado: Praça Principal, Praça João Pessoa, Praça da Liberdade e Praça Benedito Valadares. O nome "Praça Principal" ainda é muito popular entre os bocaiuvenses, uma vez que localiza-se no centro da cidade e por ser o lugar dos acontecimentos mais importantes, desde a sua criação. É ponto de encontro, espaço de convergência de fluxos de pessoas, palco de festividades, manifestações populares e lazer de crianças, jovens e adultos. A Praça WanDyck Dumont mexe com o imaginário da população por ser um ponto de referência e por ter passado por reformas marcantes ao longo dos anos. Algumas delas não foram muito aceitas, sobretudo por moradores mais velhos, sendo motivo de lamentações pela perda das características originais.

Figura 3 - Praça WanDyck Dumont ates da década de 1930

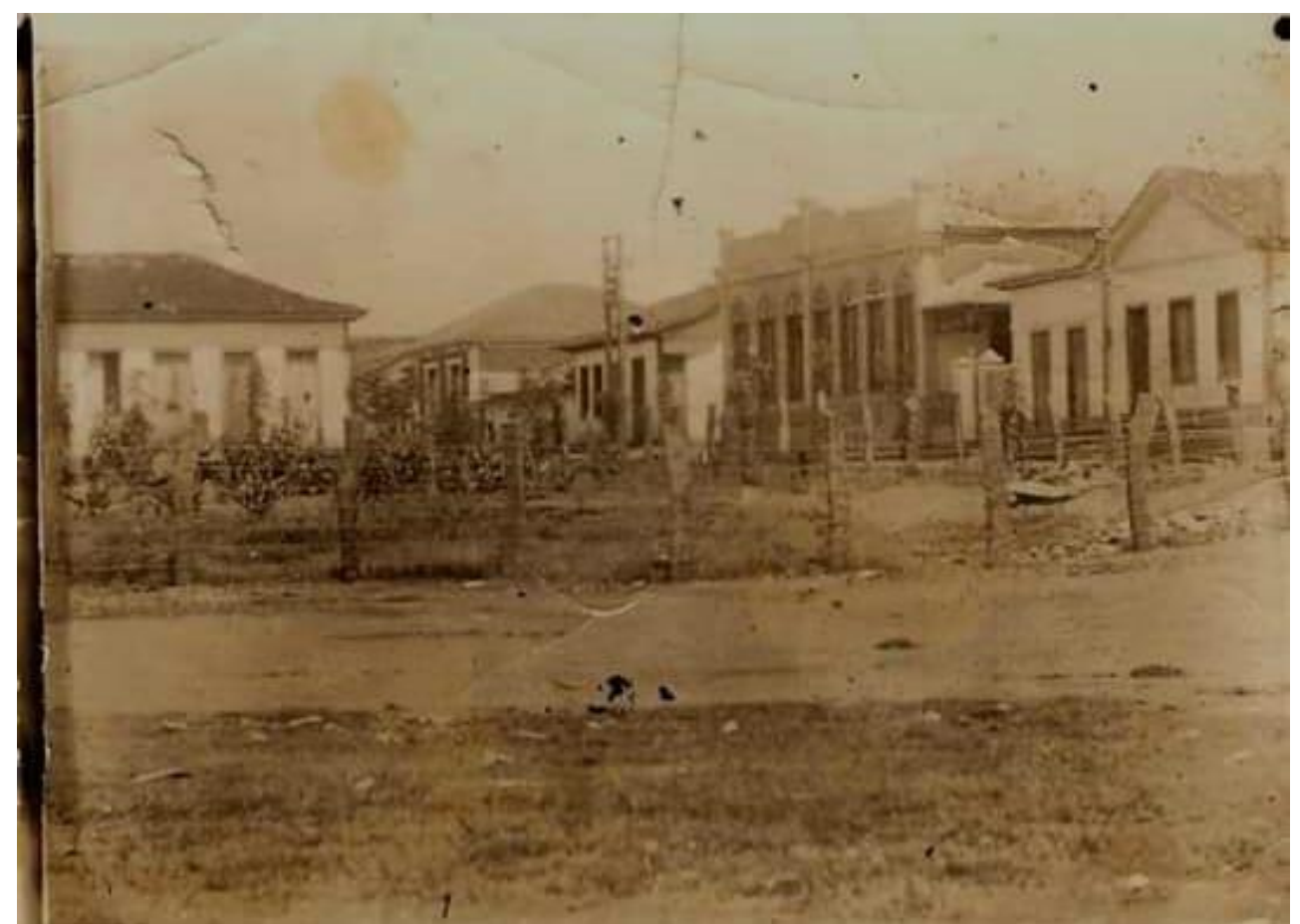

Fonte: Fonte: Acervo da historiadora Bim Brandão 
A primeira reforma aconteceu na década de 1930, durante o mandato do prefeito Gilberto Caldeira Brant, o "Seu Nem", eleito em 1934. Essa reforma está entre as principais obras realizadas por ele, que mandou colocar vários bancos no seu interior além de jardins, árvores e um coreto, que ficava no centro da praça (RIBEIRO, 1988). A paisagem da praça era composta pelo antigo mercado municipal (figura 4), originalmente construído onde hoje passa a Avenida Francisco Dumont, mas demolido e realocado próximo à escola Genesco Augusto Caldeira Brant, na década de 1960, ainda no centro, porém um pouco distante do seu lugar de origem.

O mercado era o ponto de trocas comerciais e o elo entre o campo e a cidade; foi nesse local que surgiu a principal área comercial da cidade. Próximo à praça, ainda na década de 1930, consoante a Amorim (1999), foi fundado o Bocaiuva Clube, que era o centro da vida social das classes mais abastadas. Ainda em conformidade com o mesmo autor, encontram-se relatos de que com a construção do Clube, os preconceitos raciais e sociais eram mais evidentes. Os moradores mais pobres e negros não eram bem aceitos nesses lugares frequentados por uma suposta elite local, assim sendo, "as moças 'de primeira' passeavam no jardim da praça central, enquanto as 'de segunda' frequentavam os jardins da praça dos coqueiros ou o 'Jardim-de-Cima'" (AMORIM, 1999, p.77), . Demonstrando interesse acerca das questões históricas da cidade o entrevistado C comenta que:

Procurei saber das pessoas mais velhas e historiadores da cidade, alguns aspectos sobre a atual praça central da cidade, que primeiramente se chamou Praça Principal, depois Praça da Liberdade, em seguida Praça Benedito Valadares e agora WanDyck Dumont. Pelas fotos a mim apresentadas, gostei mais da foto da década de 1940, quando ela se apresentava com muitos jardins, árvores circundando-a, um coreto de alvenaria e vários bancos espalhados no seu interior.

Ainda sobre essa época, tanto a entrevistada A quanto a entrevistada B têm a lembrança do antigo coreto muito vívida em suas memórias. Ao ser questionada sobre suas lembranças dessa praça, a primeira se posiciona: "A 
memória é de um tempo de maior integridade e reciprocidade. $O$ encontro se dava no coreto e em sua volta. A banda tocava e as moças ficavam dando voltas na praça". Já a entrevistada B se lembra de outros elementos: "As árvores, as plantas caracterizavam a praça do interior. O Mercado Municipal, nos sábados, determinava a economia agrícola e a integração com o campo. O Bocaiúva Clube era o sonho jovem e social".

Figura 4 - Coreto da Praça WanDyck Dumont, década de 1940

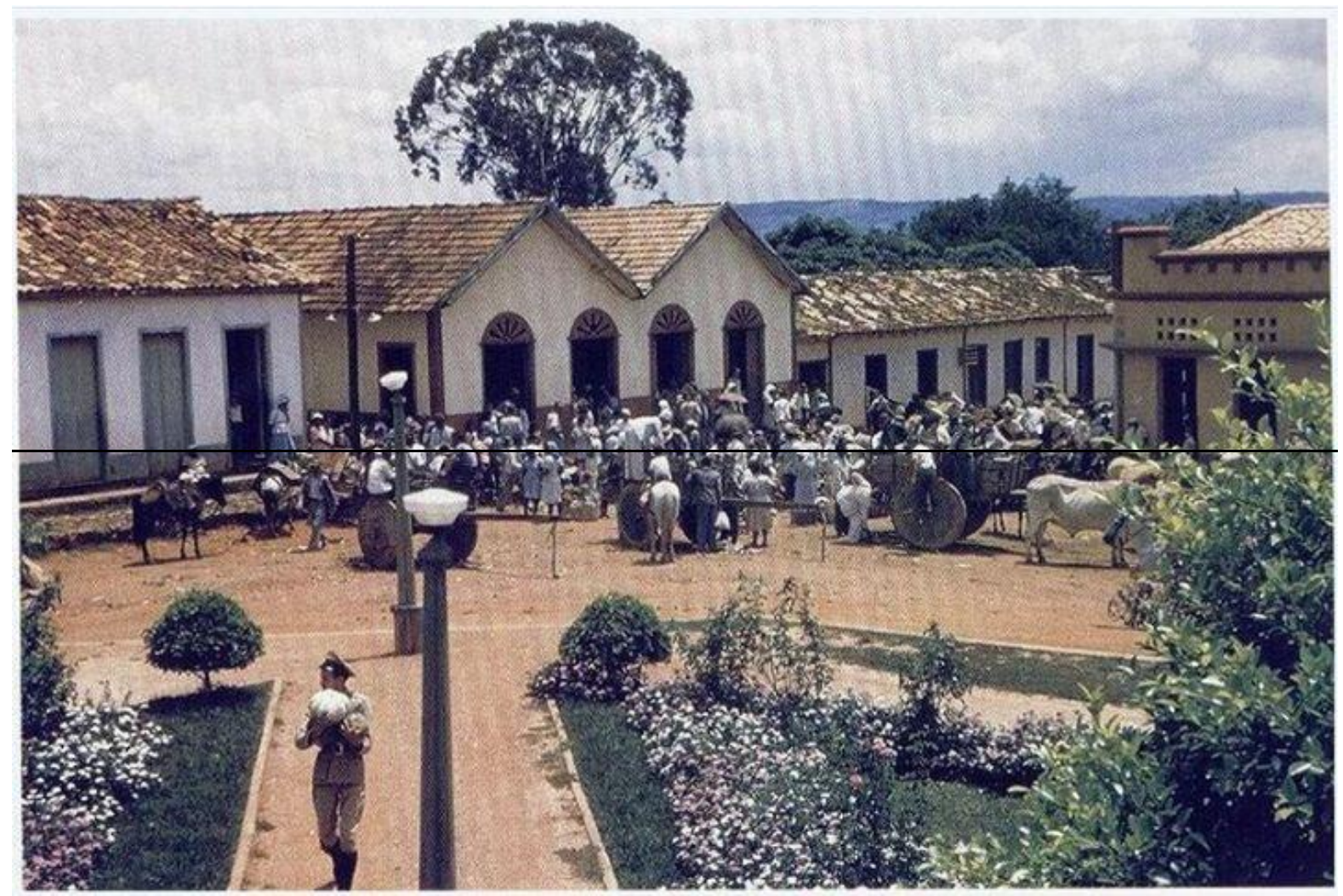

Fonte: Fonte: Acervo da historiadora Bim Brandão

Ao longo do tempo, o centro da cidade passou por modificações em sua estrutura. As primeiras reformas urbanas nessa área ocorreram na década de 1960 e mudaram a sua dinâmica e o funcionamento. Segundo Alves (2013, p.5),

A década de 60 marca algumas intervenções do poder público na paisagem urbana com a construção do mercado municipal que retirou a feira do centro da cidade e transformou a área em que esta se realizava numa das principais avenidas da cidade, além de introduzir calçamento de bloquetes, substituindo o calçamento de paralelepípedo e, alterações na 'praça principal' onde se inseriu uma fonte luminosa. 
De acordo com Vieira (1996), no ano de 1963 o então prefeito WanDyck Dumont deu início à obra de calçamento de Bocaiuva, incluindo a referida praça que, na época, era denominada Benedito Valadares. Segundo a autora, "quando inaugurou o calçamento da praça, ele, na sua cordialidade, cavalheirismo e simpatia, ofereceu-o às moças da cidade, a fim de que elas pudessem passear, andar em uma praça calçada, que fosse mais digna delas" (1996, p. 89). Ao elencar as principais obras de cunho urbanístico durante o mandato do prefeito supracitado também Ribeiro (1988, p.138) cita a reforma da praça.

Conforme as informações obtidas verificou-se que a Praça WanDyck Dumont passou por sucessivas reformas, ao longo de sua história, que mudaram suas características originais. Na década de 1960, o prefeito da época, WanDyck Dumont substituiu o coreto que ficava na parte central da praça, por uma fonte luminosa (figura 5).

\section{Figura 5 - Praça WanDyck Dumont com a fonte luminosa}

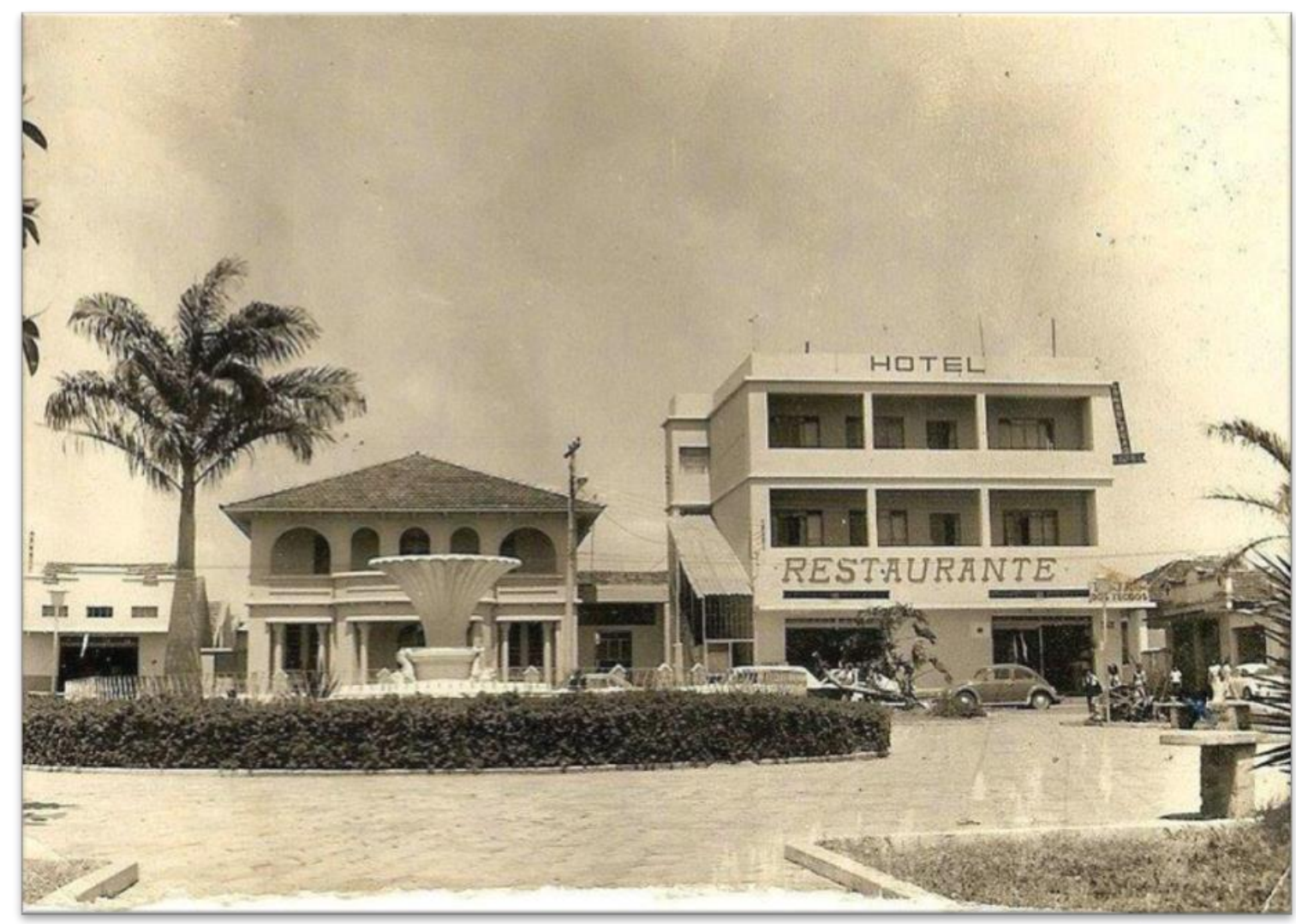

Fonte: Acervo pessoal de Bim Brandão. 
O entrevistado C traz em sua fala essa transição da antiga praça com o coreto para uma praça mais moderna e com elementos mais atraentes. Segundo ele,

Esta praça foi inteiramente demolida pelo dinâmico prefeito, o saudoso WanDyck Dumont e outra foi totalmente edificada, seguindo o lema de modernidade implantada pelo prefeito. O seu marco principal ficou por conta de uma fonte luminosa - erguida na parte central da praça, que se tornou um ponto de atração para toda população bocaiuvense.

Os costumes relatados pelos entrevistados mostram que a praça, depois da primeira reforma, ainda era o principal ponto de encontro para os moradores. A entrevistada B, chama a atenção para o ritual de paquera, conhecido popularmente por "footing". Para serem cortejadas, as moças se posicionavam no centro da praça, enquanto os rapazes davam voltas em torno delas, até haver uma troca de olhares e um consentimento cordial para acompanhá-las em um passeio pela praça. Para essas pessoas, momentos como estes eram o que definia, até certo ponto, as principais relações entre pessoas, era "o lugar onde tudo acontecia" (Entrevistada B, 73 anos).

Após a década de 1960, a praça passou por duas pequenas reformas, uma em 1988 e outra em 1990. Apesar das mudanças, as características marcantes da praça foram mantidas, como a "fonte luminosa central, caramanchão, velhos bancos de sempre, uma palmeira que resistiu às intempéries do tempo e da ação humana, uma velha castanheira (que desapareceu em 1995 com a reforma radical operada na praça)". (ALVES, 2013, p.7)

A reforma mais contundente foi no ano de 1995 e é lembrada pelo entrevistado C que comenta:

À bem da verdade tais reformas já vêm de longe. A última, de maior porte depois da de Wan-Dyck, teria sido no governo do prefeito Fernando Calixto, que aumentou o seu interior implementando mais áreas cimentadas, além de ter construído mais alguns canteiros nela. O prefeito Ricardo Veloso, cujo mandato terminou recentemente, deu alguma arrumação nos seus bancos, assim como a colocação de diversos afrescos lá. 
18 | Memória e espaço público: reflexões sobre a praça Wandyck Dumont em Bocaiuva - MG e as suas reformas ao longo do tempo

Nesta época a fonte luminosa foi retirada e em seu lugar foi instalado um poste para iluminação, além disso, foram alterados os canteiros, que ficaram mais altos e com nova vegetação, o mobiliário urbano e a paginação de pisos novos. Esses elementos implementados compõem a praça até os dias de hoje (figura 6), salvo as pequenas reformas mencionadas anteriormente pelo entrevistado.

Figura 6 - Praça WanDyck Dumont com poste central que substituiu a fonte luminosa

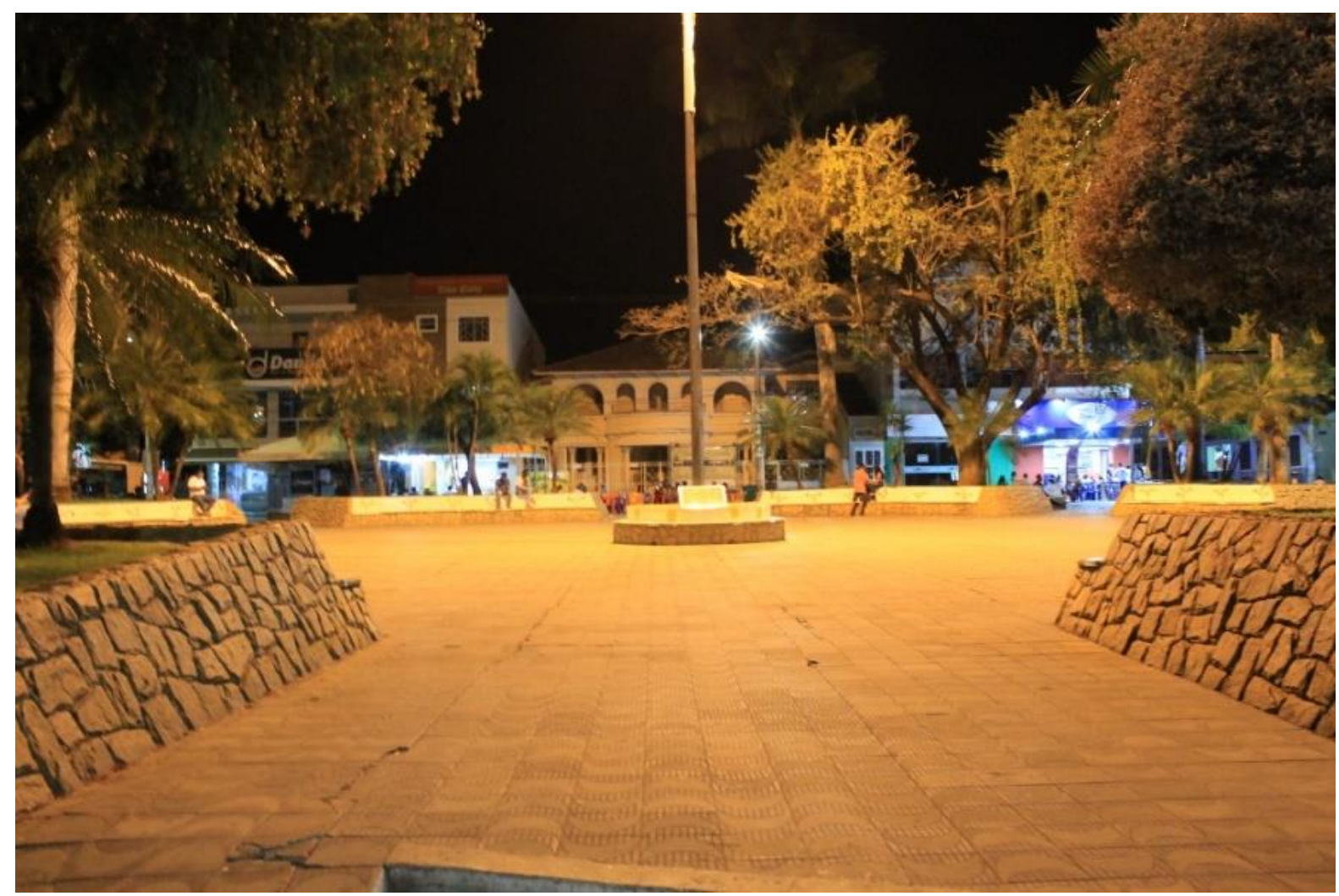

Fonte: Acervo particular dos autores, (setembro de 2019)

Ao ser questionada sobre as modificações ocorridas na praça, a entrevistada A emitiu a seguinte opinião:

Não acho que as reformas foram justas. O povo nunca foi consultado. Para mim, ela [a praça] regrediu, em especial, no aspecto histórico. Imagine um lugar com coreto, flores, árvores frondosas, residências coloniais - seria hoje um refúgio turístico, uma memória viva do início do povoamento em 1700 . O que não falta é espaço para crescimento em áreas circunvizinhas. 
Tal posicionamento está de acordo com o que é abordado por Alves (2013, p. 5), quando ela afirma que "a praça central, palco de tantas histórias, tem sido alvo de constantes intervenções arquitetônicas, sofrendo processo de descaracterização e perda da identidade, sem elo com o passado e a paisagem da cidade". A entrevistada B (73 anos) também acresce nessa discussão, afirmando: “eu sou inteiramente contra a mudança que aconteceu na praça [...] Eu queria que ainda existisse o coreto, eu morro de saudade desse tempo". Verifica-se, a partir dessa fala, que ainda há um descontentamento em relação às mudanças feitas na praça. Não houve a participação popular nas decisões urbanísticas, o que seria o ideal nos espaços de dimensão pública, como a praça. A substituição da fonte luminosa por um poste de luz, a reformulação dos canteiros e a demolição dos caramanchões (pergolados) são mudanças perceptíveis quando é feita a análise comparativa entre as fotos do passado e a atual.

A imagem da praça da década de 1960 é a mais marcante dentre as citadas e pode-se dizer que permeia a memória de boa parte da população. Fotografias dessa época são facilmente encontradas nos acervos pessoais dos bocaiuvenses, em redes sociais e também estampadas em pontos comerciais da cidade (Figura 7).

Figura 7 - Fotografia da Praça WanDyck Dumont exposta em um supermercado local

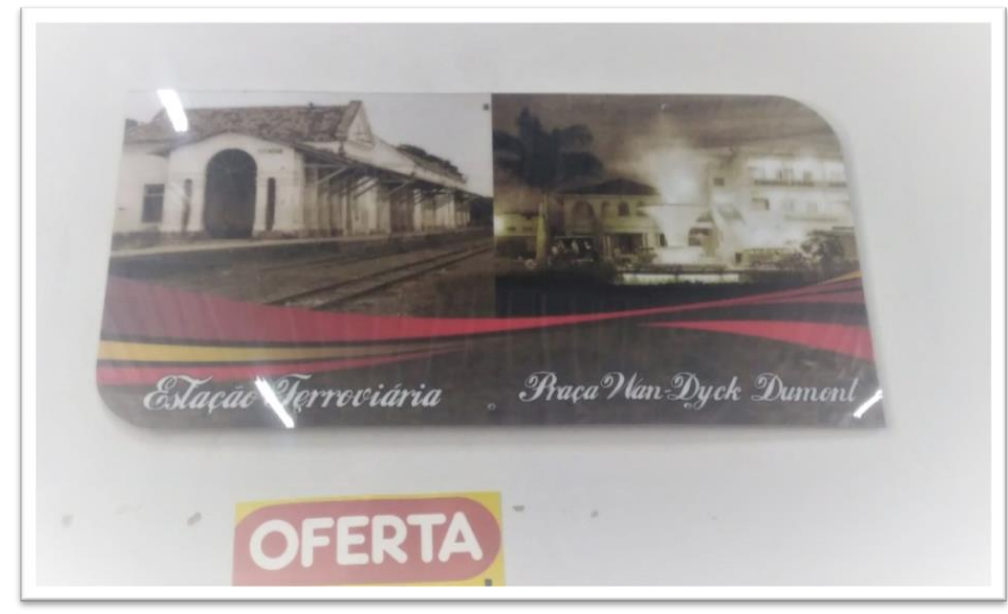

Fonte: Acervo particular dos autores, (janeiro de 2019) 
20 | Memória e espaço público: reflexões sobre a praça Wandyck Dumont em Bocaiuva - MG e as suas reformas ao longo do tempo

\section{Os participantes foram convidados a comparar a Praça WanDyck} atualmente, com a que permeia a memória de cada um deles. Cada entrevistado analisou a praça sob perspectivas diferentes, mas com um elemento comum em todas as falas: o saudosismo quanto às dinâmicas e elementos estruturais do passado.

Antes, um lugar de encontro. De sombra, acolhimento, humanizada, até antes da sua mudança mais radical. Hoje ainda é um lugar de encontro, mas de preocupação quanto à segurança. Lugar de música eletrônica, de sorvete artificial, de bares com Coca-Cola e bebidas alcoólicas. (Entrevistada A, 66 anos)

Em termos de atender à população, hoje é mais frequentada. Atualmente, Bocaiúva é mais eclética e há um maior entrosamento cultural independente de raça, cor, de dinheiro. As pessoas são mais entrosadas. Mas, em compensação [...] o povo de Bocaiuva é muito desapegado com o passado [...] a memória da cidade e a cultura daqui acabaram. (Entrevistada B, 73 anos)

A chamada primeira Praça de Bocaiuva foi erguida na década de 1930 pelo prefeito Gilberto Caldeira Brant - Seu Ném - e atingiu o seu apogeu nos anos de 1940/1950. Segundo os saudosistas, não deveria ter sido demolida totalmente, mas adaptada aos tempos modernos e progressistas, que foram alavancados pelo glorioso prefeito WanDyck Dumont. Ao seu redor havia uma área de terra batida, onde aconteciam os footings dominicais. Afora os seus grandiosos canteiros e jardins de rosas e outras tantas flores. Antes, nos anos de 1960 e alguns seguintes, a praça possuía a Fonte Luminosa, que ainda dava um tom ameno e romântico ao logradouro. A partir dos anos de 1990 até hoje, o cimento tem amplo domínio nela. (Entrevistado C)

O que é perceptível na fala dessas pessoas é que a descaracterização da praça foi uma perda para Bocaiúva. Tal foi considerado por Amorim (1999, p.93) como "subdesenvolvimento cultural" da cidade, referindo-se também à antiga igreja do Nosso Senhor do Bonfim, demolida em 1979.

A Praça WanDyck Dumont modernizou-se e tem uma dinâmica bem diferente de antes, mas ainda continua sendo um ponto de encontro e de referência para toda a população bocaiuvense. Hoje, é circundada por estabelecimentos comerciais e antigas construções, que são atrativos para as pessoas. No passado, as interações aconteciam mais espontaneamente e também em função dos eventos sociais promovidos pelo Clube da Cidade, ainda existente, mas com pouco destaque. O antigo prédio da prefeitura, com outra 
funcionalidade, também compõe a paisagem urbana do entorno da praça. Tanto o Clube quanto o prédio da prefeitura fazem parte da história da cidade e, se bem aproveitados, poderão dinamizar ainda mais o espaço atraindo novos usos e dinâmicas diversificadas.

Encontramos em Alves (2013, p.5), o termo "praça principal", que frequentemente é utilizado pela população bocaiuvense, não somente em referência ao seu antigo nome, mas também devido à sua importância para a cidade e localização na área central. Segundo o entrevistado C, “a nossa praça principal sempre foi usada por diversas manifestações sociais, cívicas, políticas, carnavalescas, festas religiosas, entre outras. A tradicional Festa do Milho nasceu lá, com pequenas barracas de produtos da zona rural". Já a entrevistada A aponta a praça como "um lugar com grande poder devido à capacidade de centralização populacional, visibilidade social e econômica".

As falas transcritas dos entrevistados revelam observações que vão além das reformas estruturais e englobam também a maneira com que a praça vem sendo utilizada pelas pessoas, nos dias de hoje. Junto ao tempo, hábitos, costumes e a forma dos espaços públicos mudam naturalmente. Entende-se que não é possível recuperar essas áreas e reviver as antigas atividades, que muitas vezes não condizem com a realidade atual. Entretanto, faz-se necessário encontrar novos usos e novas atividades que tragam vida para esses espaços sem perder os traços da sua identidade (LERNER, 2005). É uma mescla entre elementos do passado e da contemporaneidade que faz com que o espaço seja memória viva, sem deixar de acompanhar o curso natural da vida, que exige mudanças.

\section{CONSIDERAÇÕES FINAIS}

As mudanças que ocorrem na cidade acontecem, muitas vezes, de maneira muito rápida e é inegável que imprimem sentimento de perda de características 
22 | Memória e espaço público: reflexões sobre a praça Wandyck Dumont em Bocaiuva - MG e as suas reformas ao longo do tempo

do passado, fazendo com que a população de um determinado lugar retome constantemente à memória, em busca de elementos que possibilitem a recomposição de sua identidade. Em Bocaiuva é notório que esse processo é comum entre os moradores mais antigos.

À medida que o espaço público assume novas formas e significados na malha urbana, algumas pessoas que possuíam afeições por determinados lugares sentem-se injustiçadas por não terem, na cidade, referências de seu tempo. Esses lugares são pontos fundamentais de identidade, do sentimento de pertencer a uma cidade.

O presente artigo evidenciou as reformas ocorridas na Praça WanDyck Dumont ao longo dos anos, identificando alguns elementos que foram criados e outros que foram deixados para trás. A opinião de moradores mais velhos da cidade serviu de balizador para aferir a cronologia das modificações, bem como se elas trouxeram algum dano à memória da cidade. Os discursos analisados mostraram a importância do desenvolvimento e modernização da cidade, porém, ratificaram que esse processo poderia ter acontecido de forma mais respeitosa à opinião pública. Alguns entrevistados se mostraram insatisfeitos com as mudanças, sendo que alguns responsabilizaram a própria população por não se opor de maneira mais efetiva a essas ações, fato decorrente de uma cultura de participação popular ainda muito incipiente na época em que as reformas mais radicais aconteceram.

Os entrevistados se posicionam de forma crítica em relação às reformas e apelam para uma valorização maior da história da cidade. Por ser um lugar de importância para a memória dos moradores, a Praça WanDyck deveria ter suas características principais preservadas. Hoje, parte da população tenta resgatar a memória da antiga praça divulgando fotografias em suas redes sociais, pontos comerciais, ou disponibilizando-as para produções científicas que ajudam a registrar, na literatura, a memória dos espaços públicos da cidade. 
Portanto, conclui-se que a pesquisa foi fundamental para entender os significados por trás de cada reforma estrutural da praça. O trabalho colocou em evidência as narrativas de pessoas que testemunharam todas essas transformações e possibilitou reflexões a respeito do destino dos espaços públicos da cidade. As questões levantadas aqui servem de base para que outros trabalhos acadêmicos sejam desenvolvidos e, sobretudo, que o conteúdo aqui expresso seja capaz de inspirar atitudes mais conscientes em projetos de reformas de espaços que dizem respeito a uma dada população.

\section{REFERÊNCIAS}

ABREU, Maurício. Sobre a memória das cidades. In: CARLOS, Ana Fani Alessandri; SOUZA, Marcelo Lopes de; SPOSITO, Maria Encarnação Beltrão (org.). A produção do espaço urbano: agentes e processos, escalas e desafios. São Paulo: Contexto, 2016.

ALEX, Sun. Projeto da praça: convívio e exclusão no espaço público. São Paulo: Editora Senac, 2011.

ALVES, Renata Mirian. Bocaiuva: Um Cenário Épico Resguardado em Memórias. In: XVIII ENCONTRO REGIONAL (ANPUH - MG), 1, Mariana, 2012. Dimensões do poder na história. Ouro Preto: EDUFOP, 2013. P.1-10.

AMORIM, João Roberto Drumond. Oligarquias, coronelismo, caciques e populistas. Montes Claros: Editora Unimontes, 1999.

ANDRADE, Luciana Teixeira de; BAPTISTA, Luís Vicente. Espaços públicos: interações apropriações e conflitos. Sociologia, Revista da Faculdade de Letras da Universidade do Porto, Vol. XXIX, p. 129-146, 2015.

ARANTES, Antonio. Paisagens paulistanas: transformações do espaço público. Campinas: Ed. Unicamp, 2000.

BORTOLO, Carlos Alexandre de. O espaço público do Parque do Povo - Presidente Prudente SP: Reflexões Geográficas. GeoAtos - Revista de Geografia em Atos, Presidente Prudente, n.13, v.1, p. 50-65, 2013 a.

BORTOLO, Carlos Alexandre de. O Parque do Povo em Presidente Prudente-SP: Reflexões Geográficas. Revista Percurso - NEMO, Maringá, v.5, n.2, p.47-71, $2013 b$.

BOSI, Ecléa. Memória da cidade: lembranças paulistanas. Estudos Avançados. Abr 2003, vol.17, no.47, p.198-211. ISSN 0103-4014. 
BRASIL. Estatuto da Cidade: Lei 10.257/2001. Estabelece diretrizes gerais da política urbana. Brasília, Câmara dos Deputados, 2001, 3a Edição.

CARLOS, Ana Fani Alessandri. A condição espacial. São Paulo: Contexto, 2016.

DELGADO, Lucilia de Almeida Neves. História oral: memória, tempo, identidades. Belo Horizonte: Autêntica, 2006. 135 p.

DIAS, Marina Simone; JúNIOR, Milton Esteves. O espaço público e o lúdico como estratégias de planejamento urbano humano em: Copenhague, Barcelona, Medelín e Curitiba. Cadernos Metrópole, São Paulo, v.19, n.39, p.635-663, mai/ago 2017.

FREIRE, Doia; PEREIRA, Lígia Leite. História Oral, Memória e Turismo Cultural. In: MURTA, Stela Maris (org.); ALBANO, Celina (org.). Interpretar o Patrimônio um exercício do olhar. Belo Horizonte: Ed. UFMG; Território Brasilis, 2002.

GEHL, Jan. Cidades para pessoas. São Paulo: Perspectiva, 2015.

GOMES, Paulo Cesar da Costa. Espaço Público, Espaços Públicos. GEOgraphia, Niterói, v. 20, n. 44, p. 115-119, 2018.

INSTITUTO BRASILEIRO DE GEOGRAFIA E ESTATÍSTICA - IBGE. Censo Demográfico, 1970-2010. Disponível em < www.ibge.gov.br> Acesso em: abril, 2019.

JACOBS, Jane. Morte e vida de grandes cidades. São Paulo: Martins Fontes, 2000.

LEFEBVRE, Henri. La production de I’espace, 4e édition. Paris: Anthropos, 2000.

LEITE, Rogério Proença. Contra-usos e espaço público: notas sobre a construção social dos lugares na Manguetown. Revista Brasileira de Ciências Sociais, São Paulo, n. 49, v. 17, p.115-172, 2002.

LERNER, Jaime. Acupuntura urbana. Rio de Janeiro: Record, 2005.

LIPAI, Alexandre Emílio. Metrópole e as múltiplas dimensões do espaço público: Praça da Sé, São Paulo, Brasil. Disponível em <http://www.vitruvius.com.br/revistas/read/arquitextos/06.068/392> Arquitexto 68. Janeiro, 2006. Acesso em: agosto, 2019.

OLIVEIRA, Pedro Henrique Inácio de. Influência de Montes Claros sobre o fluxo pendular de Bocaiúva. Trabalho de conclusão de curso, Departamento de Geografia UFV, 2017.

ORTEGOSA, Sandra Mara. "Cidade e memória: do urbanismo "arrasa-quarteirão" à questão do lugar". Arquitextos, ano 10, n. ${ }^{\circ}$ 112.07. [Em linha] São Paulo: Vitruvius, Setembro 2009. Disponível em https://www.vitruvius.com.br/revistas/read/arquitextos/10.112/30. Acesso em abril de 2019. 
RIBEIRO, Eliane Maria Fernandes. Bocaiúva: Sociedade e Espaço. Belo Horizonte: Graphilivros Editores Ltda, 1988.

SERPA, Angelo. Espaço público e acessibilidade: Notas para uma abordagem geográfica. GEOUSP - Espaço e Tempo, São Paulo, № 15, pp. 21 - 37, 2004

SOBARZO, O. A produção do espaço público: da dominação à apropriação. GEOUSP Espaço e Tempo, São Paulo: [s.n.], n.19, p.93-111, 2006.

SOUZA, Mariana Jantsch. A memória como matéria prima para uma identidade: apontamentos teóricos acerca das noções de memória e identidade. Revista Graphos, vol. 16, $\mathrm{n}^{\circ} \quad 1$ 2014. Disponível em https://periodicos.ufpb.br/index.php/graphos/article/view/20337. Acesso em Agosto de 2019.

VIEIRA, Maria Clara Lage. Wan-Dyck, pintor de simpatia. Copyright by Maria Clara Lage Vieira, 1996.

VILLAÇA, Flávio. A crise do Planejamento Urbano. São Paulo em perspectiva, São Paulo: Fundação Seade, v. 9, n.2, p. 45-51, abr/jun. 1995. 